\title{
Erratum to: Optimizing the Terzaghi Estimator of the 3D Distribution of Rock Fracture Orientations
}

\author{
Huiming Tang ${ }^{1} \cdot$ Lei Huang $^{1,2}$ (C) $\cdot$ C. Hsein Juang ${ }^{2} \cdot J^{\prime}$ unrong Zhang ${ }^{1}$
}

Published online: 3 July 2017

(c) Springer-Verlag GmbH Austria 2017

\section{Erratum to: Rock Mech Rock Eng \\ DOI 10.1007/s00603-017-1254-7}

In the original article, Fig. 10 is published incorrectly. The correct figure is given below (Fig. 10).

The online version of the original article can be found under doi:10.1007/s00603-017-1254-7.

Lei Huang

huanglei@cug.edu.cn

1 Department of Geotechnical Engineering and Engineering

Geology, Faculty of Engineering, China University of

Geosciences, Wuhan 430074, Hubei, China

2 Glenn Department of Civil Engineering, College of Engineering, Computing and Applied Sciences, Clemson University, Clemson, SC 29634, USA 
(a) Location 103 $13^{\circ}$

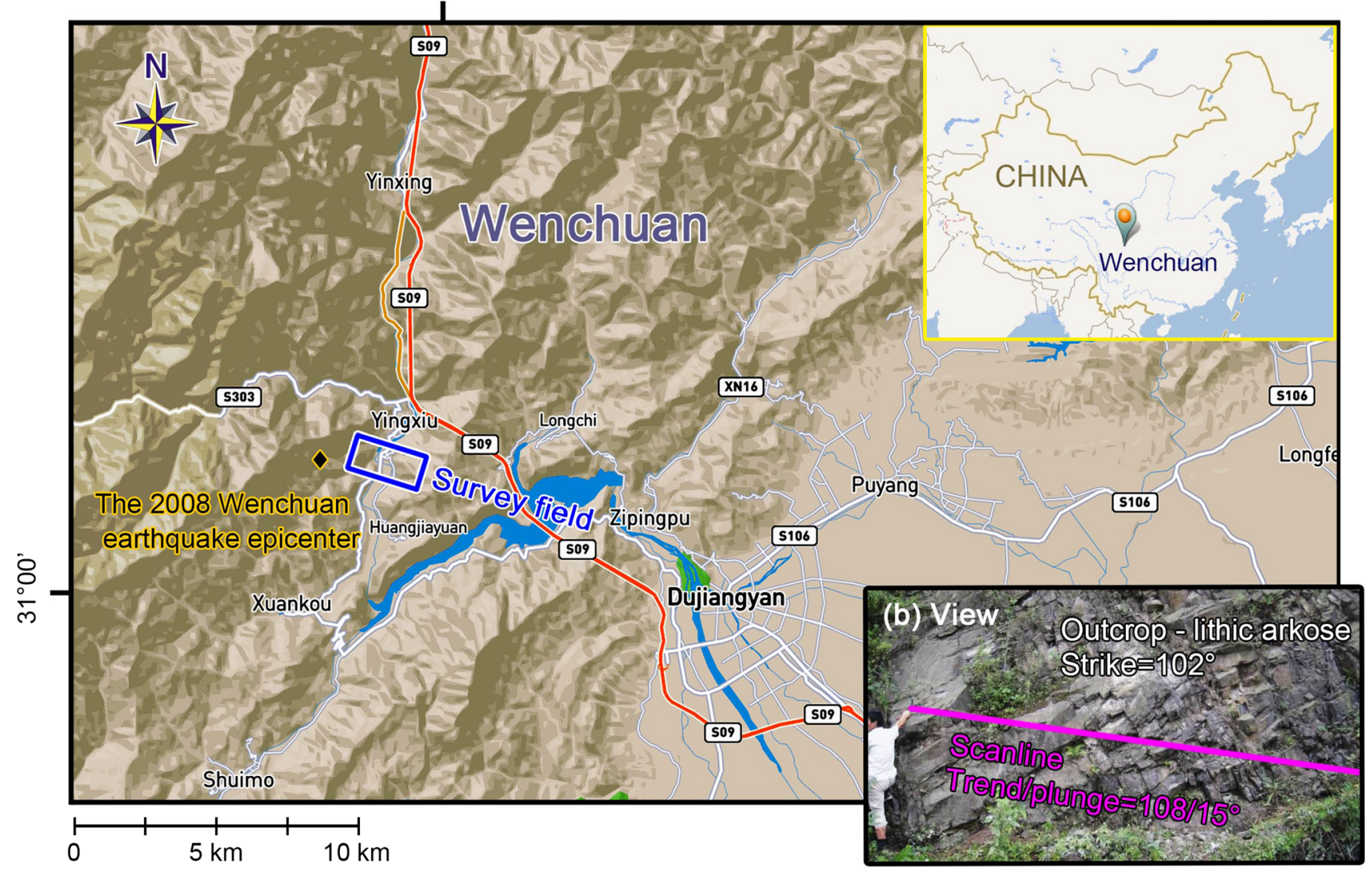

Fig. 10 a Location of the survey field. The site is near the town of Yingxiu in Wenchuan, Sichuan Province, China, approximately $1800 \mathrm{~m}$ east of the 2008 Wenchuan earthquake epicenter. b View

of the survey field. This nearly vertical outcrop $(11 \mathrm{~m}$ long, $5 \mathrm{~m}$ wide, and $6 \mathrm{~m}$ high) strikes at $102^{\circ}$ and develops in the upper Triassic lithic arkose of the Xujiahe Formation 